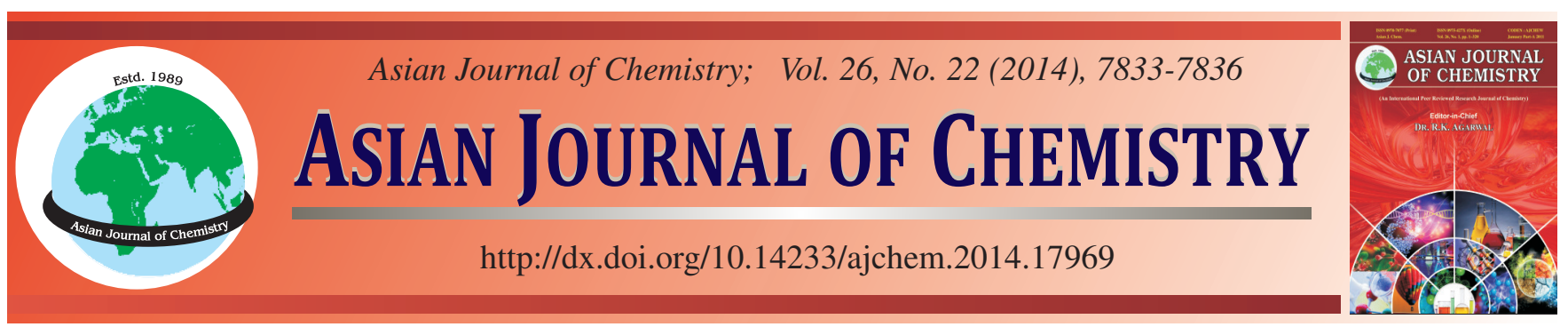

\title{
Preparation and Characterization of Activated Carbon from Date Fronds Biomass by Chemical Activation
}

Ashfaq Ahmad, Hassan M. Al-Swaidan* and Ahmad H. Alghamdi

Department of Chemistry, College of Science, King Saud University Riyadh, P.O.Box 2455, Riyadh-11451, Kingdom of Saudi Arabia

*Corresponding author: Fax: +966 11 4674365; Tel: +966 11 4676008; E-mail: hswaidan@ksu.edu.sa

Received: 8 May 2014;

Accepted: 15 July 2014;

Published online: 6 November 2014;

AJC-16245

Date's frond wastes have been used to prepare activated carbons. Methods of production and types of waste materials have an effect on the properties of activated carbons. Date's tree frond waste is a biomass and used as a precursor to prepare activated carbon by chemical activation with $\mathrm{KOH}$ is reported in this work. The characterization of carbon materials is performed by Fourier transform infrared spectroscopy, scanning electron microscopy and nitrogen adsorption. The char was obtained from date fronds at $400{ }^{\circ} \mathrm{C}$ temperature which corresponds to thermogravimetry analysis. A high surface area porous activated carbons was prepared by soaking the date's frond in $\mathrm{KOH}$ solutions. A variety of $\mathrm{KOH}$ concentrations such as $0,5,10$ and $15 \%$ are used. The $15 \%$ concentration of $\mathrm{KOH}$ was found the best with the highest surface area $250.25 \mathrm{~m}^{2} \mathrm{~g}^{-1}$. The FTIR analysis indicates several functional groups changes on the surface of the activated carbons which are formed during different preparation phases. JSM-scanning electron microscopy of activated carbons indicates cavities and pores on the surface. The maximum BET surface area $250.25 \mathrm{~m}^{2} \mathrm{~g}^{-1}$ was found for $15 \% \mathrm{KOH}$ activated carbons compared to raw date fronds $4.6 \mathrm{~m}^{2} \mathrm{~g}^{-1}$.

Keywords: Activated carbon, Date fronds, Chemical activation, Potassium hydroxide, Surface area.

\section{INTRODUCTION}

Activated carbon is an outstanding adsorbent because of its high-quality adsorption properties. Activated carbon (AC) can be synthesized from carbon containing ancestor materials such as agricultural by-product biomasses and their wastes, wood and some polymers. Activated carbons have been used extensively in various industries for the decolorization, purification, separation and deodorization of fats and vegetable oils, water purification and pollution treatment, gas and air purification, pharmaceutical and food ${ }^{1-3}$. Due to low cost agricultural by product biomasses and their wastes are getting more importance. Activated carbons can be prepared from different carbon containing materials such as coal, wood, lignin, shells (coconut, walnut, palm, pecan, almond, physic nut), cotton stalks, corn cob, chickpea husk, tobacco stems, sugar cane bagasse, date stones and cherry stones etc. ${ }^{4-20}$.

The commonly used chemical agents to activate various biomasses are $\mathrm{H}_{3} \mathrm{PO}_{4}{ }^{3,5,6,11,14}, \mathrm{KOH}^{1,4,15,21,22}, \mathrm{~K}_{2} \mathrm{CO}_{3}^{2,6,15-17,22}$, $\mathrm{NaOH}^{22}, \mathrm{Na}_{2} \mathrm{CO}_{3}{ }^{22}$ and $\mathrm{ZnCl}_{2}{ }^{6,4,23,24}$. Activated carbons can be prepared by two methods i.e., chemical activation and physical activation. In chemical activation method first activating the precursor (carbonaceous materials) followed by carbonization at different temperature. Physical activation involves carboni- zation at high temperature and then activation of charcoal through by activating agents like steam, $\mathrm{O}_{2}$ and $\mathrm{CO}_{2}$. The chemical activation is usually performed at lower temperatures than physical activation. The development of pores and carbon yields of chemical activation are higher than physical activation $^{25-30}$.

Date palm tree is one of the major and plenty cultivating plants in Saudi Arabia, which is more than 20 millions. The estimated date's frond is 75,000 tons per year due to cutting (pruning) process of three million date palm trees every year ${ }^{31}$. The date's fronds is sometime burnt or disposed off as waste, which is harmful to the environment.

The aim of this study is to prepare an activated carbons from date's fronds waste (biomass), which are abundant Saudi Arabian agricultural by-products, by using the chemical activation process. The influence of different concentration of potassium hydroxide as an activating agent and carbonization temperature were investigated and discussed. The characterization of activated carbons is carried out to determine the morphological and chemical changes.

\section{EXPERIMENTAL}

To prepare activated carbons, the date's fronds waste was collected from Riyadh (Kingdom of Saudi Arabia) date plants. 
The collected date's fronds were first cut it into pieces of 1-3 $\mathrm{cm}$ then washed several times with tap water followed by distilled water to eliminate all foreign materials (dust, fibers and impurities). The washed fronds are dried for $5 \mathrm{~h}$ at $105^{\circ} \mathrm{C}$ to remove any moistures content.

Preparation of activated carbon: The method of preparation of activated carbons from date's fronds waste was used by mainly consist of activation and pyrolysis. To chemically activate the precursor (date's fronds waste) $\mathrm{KOH}$ was used as an activating agent. Dried sample of date's fronds with mass $20 \mathrm{~g}$ was soaked in $200 \mathrm{~mL}$ of 5, 10 and $15 \% \mathrm{KOH}$ concentrations solution for $18 \mathrm{~h}$ at $25^{\circ} \mathrm{C}$ temperature.

The socked date's fronds were kept in Muffle furnace for $2 \mathrm{~h}$ at $110^{\circ} \mathrm{C}$ until complete dryness. After that, the date's frond in furnace was heated (carbonized) at activation temperature $400{ }^{\circ} \mathrm{C}$ for $3 \mathrm{~h}$. This activation temperature corresponds to the TGA (TA/TGA Q50) analysis for date fronds. The prepared activated carbons was swelled. The activated carbons washed with $1.5 \mathrm{~mol} \mathrm{~L}^{-1} \mathrm{HCl}$ solution to reduce the $\mathrm{pH}$. Double distilled water was used to remove the excess activating agent until $\mathrm{pH} 7$ of the washing effluent achieved. Finally the samples were dried at $105^{\circ} \mathrm{C}$ in an oven to evaporate the moisture contents.

Analysis and characterization: The contents of $\mathrm{C}, \mathrm{H}$ and $\mathrm{N}$ of the raw materials of date's fronds were measured using a CHN/CHNS/O (Parkin Elmer 2400 series) analyzer. The important information about the chemical compositions of the samples was obtained by FTIR spectrum analysis using Thermo Scientific NICOLET 6700 FTIR (Model) USA. The spectrum was recorded in a spectral range of $4000-400 \mathrm{~cm}^{-1}$. A Micromeritics Gemini VII, 2390 nitrogen $\left(\mathrm{N}_{2}\right)$ gas adsorption at $77 \mathrm{~K}$ instrument was employed for specific surface area, pore volume and pore size analyses. The specific surface areas of the samples of various $\mathrm{KOH}$ concentrations and raw date's fronds were determined using BET adsorption analysis. The SEM micrographs of the date's fronds samples were obtained using JSM-6610 scanning electron microscope.

\section{RESULTS AND DISCUSSION}

Thermogravimetric analysis: To observe the decomposition characteristic of the raw date's fronds thermal analysis was performed. The TGA curves of the date's frond waste are shown in Fig. 1. The weight losses in nitrogen atmosphere of the date's frond sample occurred in three stages. The first range of decomposition happened at $50-189.67^{\circ} \mathrm{C}$, which indicates the loss of water, some volatile and light gases. The weight loss at this stage was $4.38 \%$. The lignocellulosic structure decomposition starts above $200{ }^{\circ} \mathrm{C}^{32}$. At temperature range of $210-400{ }^{\circ} \mathrm{C}$, a major and sharp weight loss was observed. The decomposition of major components (hemicelluloses, cellulose and lignin) corresponds to this temperature range. The 2nd range is up to $347^{\circ} \mathrm{C}$ in which $54 \%$ weight loss observed and carbonization begins ${ }^{33-35}$. The weight loss in third stage from point 400 to $1000{ }^{\circ} \mathrm{C}$ slowly decreased.

Elemental composition of date's fronds: The composition of date's fronds (biomass) affects the activation and pyrolysis processes, so the elemental composition such as carbon, hydrogen and nitrogen of activated date's frond analyzed by a CHN elemental analyzer is shown in Table-1. The high

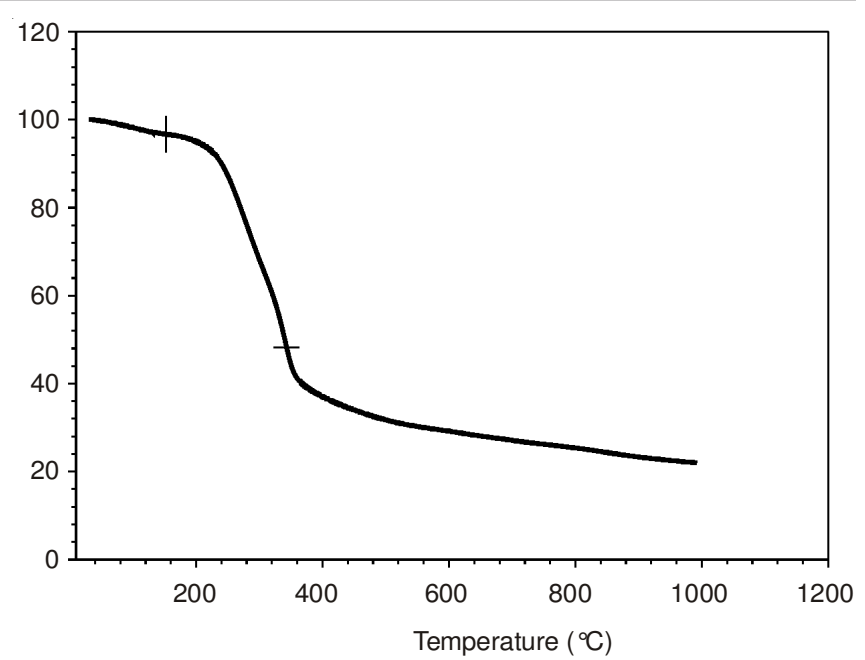

Fig. 1. TG analysis of date's frond waste

\begin{tabular}{cccc}
\multicolumn{5}{c}{ TABLE-1 } \\
\multicolumn{4}{c}{ ELEMENTAL COMPOSITION (WEIGHT \%) } \\
\hline Elements (\%) & AC 5 \% & AC10 \% & AC15 \% \\
\hline C & 73.43 & 77.29 & 78.45 \\
H & 2.67 & 2.69 & 2.77 \\
N & 0.29 & 0.20 & 0.77 \\
\hline Note: Activated carbon (AC). & &
\end{tabular}

carbon contents can be observed for $15 \% \mathrm{KOH}$, which is a high $\mathrm{KOH}$ concentration and for lower concentration the carbon contents is also lower.

BET Surface area of activated carbon for different KOH concentration: The surface area, pore volume and pore size of activated carbon produced at various concentration of $\mathrm{KOH}$ is shown in Table-2. High surface area of activated carbon was obtained with the increase of $\mathrm{KOH}$ concentration. Usually higher concentration, would improve the porosity development. Low surface area was observed for raw date's fronds $4.6 \mathrm{~m}^{2} \mathrm{~g}^{-1}$ whereas highest surface area $250.25 \mathrm{~m}^{2} \mathrm{~g}^{-1}$ was obtained for activated carbon $15 \% \mathrm{KOH}$. The high surface area of activated carbon $15 \% \mathrm{KOH}$ might be attributed to the increase pore volume.

\section{TABLE-2}

SINGLE POINT BET SURFACE AREA OF KOH ACS

\begin{tabular}{cccccc}
\hline Label & $\begin{array}{c}\text { Conc. of } \\
\mathrm{KOH}\end{array}$ & $\begin{array}{c}\text { Surface area } \\
\left(\mathrm{m}^{2} \mathrm{~g}^{-1}\right)\end{array}$ & $\begin{array}{c}\text { Pore vol. } \\
\left(\mathrm{cm}^{3} \mathrm{~g}^{-1}\right)\end{array}$ & $\begin{array}{c}\text { Pore size } \\
(\AA)\end{array}$ & $\begin{array}{c}\text { Yield } \\
(\%)\end{array}$ \\
\hline RDF & $0 \% \mathrm{KOH}$ & 4.6 & - & - & - \\
AC 5\% & $5 \% \mathrm{KOH}$ & 191.55 & 0.068 & 14.31 & 45.2 \\
$\mathrm{AC} 10 \%$ & $10 \% \mathrm{KOH}$ & 224.71 & 0.078 & 14.23 & 41.5 \\
$\mathrm{AC} 15 \%$ & $15 \% \mathrm{KOH}$ & 250.25 & 0.082 & 14.17 & 39.0 \\
\hline
\end{tabular}

Note: Raw date frond (RDF).

Fourier transform infrared spectroscopy (FTIR) analysis: Different functional groups information of the materials can be obtained by FTIR spectra. Fig. 2 illustrates the FTIR spectra of raw date frond (Raw-DF), activated carbons of date's fronds at 5,10 and $15 \%$ concentration of $\mathrm{KOH}$. All spectra show a strong absorption band between 3600$3400 \mathrm{~cm}^{-1}$, which is the characteristic of $\mathrm{OH}$ group. The broadening of the band in this region is attributed to high degree of hydrogen bonding. ${ }^{36}$ 
The raw date's frond (Raw-date frond) in Fig. 2(a) shows the most crowded and complex spectrum. A strong and broad adsorption peak appeared at $3386.23 \mathrm{~cm}^{-1}$, which is the stretching of $\mathrm{O}-\mathrm{H}$ group in the raw date frond sample. The peak observed at $2923.75 \mathrm{~cm}^{-1}$ corresponding to the alkane C-H stretching. The peaks at 1733.44 and $1618.30 \mathrm{~cm}^{-1}$ corresponds to the stretching of $\mathrm{C}=\mathrm{O}$ and $\mathrm{C}=\mathrm{C}$, respectively, whereas the peak at $1425.46-1375.25 \mathrm{~cm}^{-1}$ corresponds to $\mathrm{C}-\mathrm{H}$ bending and rocking in alkane respectively. It also shows some other important absorption peaks at 1330.98, 1160.53, 1243.99 and $1055.98 \mathrm{~cm}^{-1}$ which characterize the $\mathrm{C}-\mathrm{O}$ group. The spectrum for activated carbon $5 \%$ (b), $10 \%$ (c), $15 \%$ (d), in Fig. 2 demonstrates low absorption peaks because most of the groups are reduced. All spectrums show an $\mathrm{OH}$ group, which is probably of $\mathrm{C}-\mathrm{OH}$ bonded molecule.

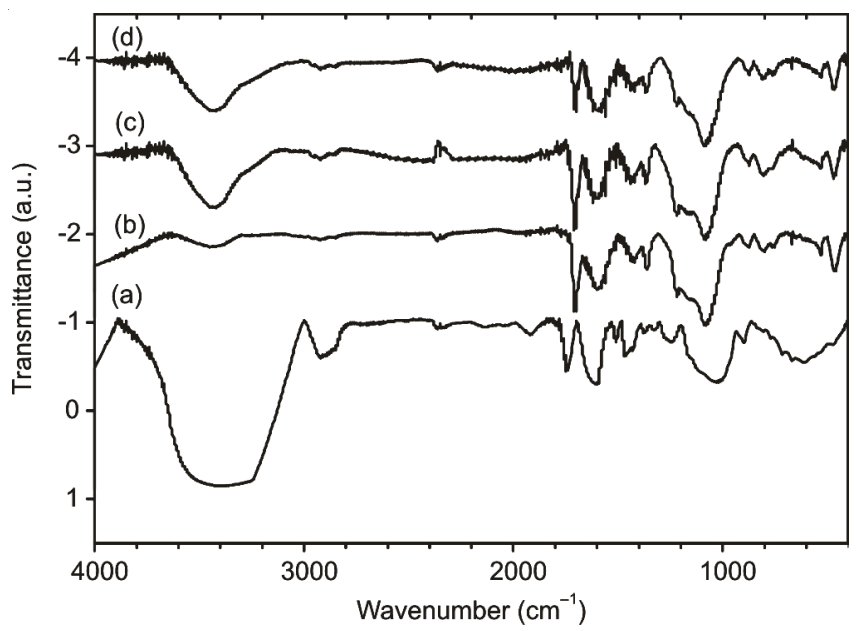

Fig. 2. FTIR spectra (a) Raw-date frond (b) activated carbon $5 \%$ (c) activated carbon $10 \%$ and (d) activated carbon $15 \%$

SEM analysis: Fig. 3 shows the scanning electron microscope (SEM) micrographs for the palm date's fronds before and after activation. All the micrographs in Fig. 3 are obtained at $500 \mathrm{x}$ magnification. Fig. 3(a) shows the micrograph of the raw date's frond (Raw-DF). It is observed that the surface of Raw-date frond is in curvy form due to cellulose, hemicelluloses and lignin and with less slit like fractures or cracks. That is the reason for lower BET surface area of the Raw-date frond. A regular development is observed in the surface morphology with increase in the $\mathrm{KOH}$ concentration. In Fig. 3(b) activated carbon $5 \%$ the growth of pores and crack formation can be observed. The activated carbon $5 \%$ has high BET surface area than Raw-date frond due to these pores. Fig. 3(d) illustrates the micrograph of activated carbon $15 \%$, which shows some extra pores and cracks. These extra pores have contributed to the high BET surface area of activated carbon $15 \%$ compared to Raw-date frond, activated carbon $5 \%$ and activated carbon $10 \%$. The clear surface of activated carbon $15 \%$ is attributed to the removal of impurities and volatile components during activation.

\section{Conclusion}

Activated carbons were prepared from the date's frond waste by combining pyrolysis at $400{ }^{\circ} \mathrm{C}$ and chemical activation with $\mathrm{KOH}$. The yields of the activated carbons produced

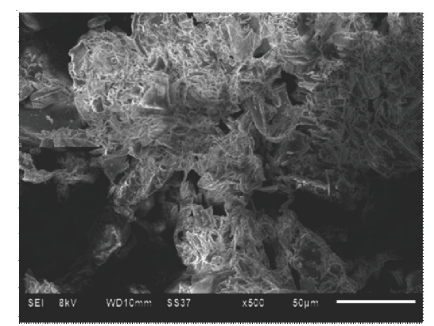

(a) Raw-date frond

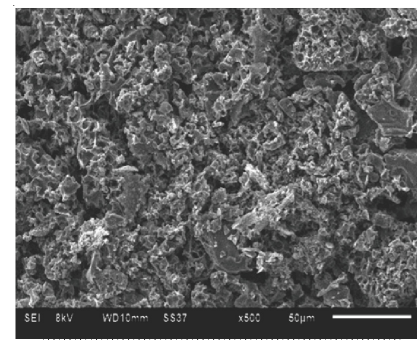

(c) activated carbon $10 \%$

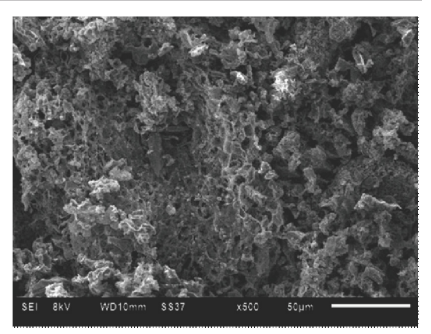

(b) activated carbon $5 \%$

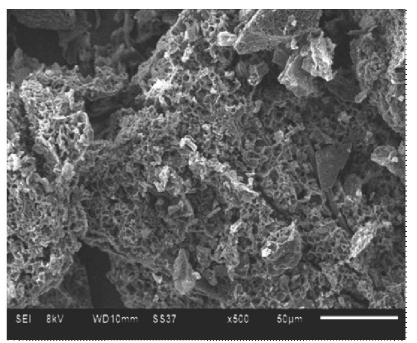

(d) activated carbon $15 \%$
Fig. 3. SEM of (a) Raw-date frond (b) activated carbon $5 \%$ (c) activated carbon $10 \%$ (d) activated carbon $15 \%$

by chemical activation were found to be higher. Elemental analyses of activated carbon have high percentage of carbon contents. Activated carbon- $15 \% \mathrm{KOH}$ shows highest surface area $250.25 \mathrm{~m}^{2} \mathrm{~g}^{-1}$ as compared to the raw date fronds. As a result, the produced activated carbons from date fronds (waste biomass) have low carbonization temperature and high surface area.

\section{ACKNOWLEDGEMENTS}

This Research was supported by King Saud University, Deanship of Scientific Research, College of Science Research Center.

\section{REFERENCES}

1. A.C. Lua and T. Yang, J. Colloid Interf. Sci., 274, 594 (2004).

2. I.I. Gurten, M. Ozmak, E. Yagmur and Z. Aktas, Biomass Bioenergy, 37, 73 (2012)

3. H.M. Al-Swaidan and A. Ahmad, In Proceedings of 3rd International Conference on Chemical, Biological and Environmental Engineering (IPCBEE), Singapore, vol. 20 (2011).

4. T. Kopac and A. Toprak, Int. J. Hydrogen Energy, 32, 5005 (2007).

5. A. Ould-Idriss, M. Stitou, E.M. Cuerda-Correa, C. Fernández-González, A. Macías-García, M.F. Alexandre-Franco and V. Gómez-Serrano, Fuel Process. Technol., 92, 261 (2011).

6. F. Wu, R. Tseng and R. Juang, Separ. Purif. Tech., 47, 10 (2005).

7. J. Hayashi, A. Kazehaya, K. Muroyama and A.P. Watkinson, Carbon, 38, 1873 (2000).

8. K. Yang, J. Peng, C. Srinivasakannan, L. Zhang, H. Xia and X. Duan, Bioresour Technol., 101, 6163 (2010).

9. M.L. Martýnez, M.M. Torres, C.A. Guzman and D.M. Maestri, Ind. Crops Prod., 23, 23 (2006).

10. A. Arami-Niya, W.M.A. Wan Daud, F. S. Mjalli, F. Abnisa and M.S. Shafeeyan, Chem. Eng. Res. Des., 90, 776 (2012).

11. Y, Guo and D.A. Rockstraw, Bioresour Technol., 98, 1513 (2007).

12. J.M.V. Nabais, C.E.C. Laginhas, P.J.M. Carrott and M.M.L. Ribeiro Carrott, Fuel Process. Technol., 92, 234 (2011).

13. D.A.Z. Wever, H.J. Heeres and A.A. Broekhuis, Biomass Bioenergy, 37, 177 (2012).

14. M.A. Nahil and P.T. Williams, Biomass Bioenergy, 37, 142 (2012).

15. W.T. Tsai, C.Y. Chang, S.Y. Wang, C.F. Chang, S.F. Chien and H.F. Sun, Bioresour. Technol., 78, 203 (2001). 
16. J. Hayashi, T. Horikawa, K. Muroyama and V.G. Gomes, Micropor. Mesopor. Mater, 55, 63 (2002).

17. W. Li, L. Zhang, J. Peng, N. Li and X. Zhu, Ind. Crops Prod., 27, 341 (2008).

18. M. Carrier, A.G. Hardie, U. Uras, J. Gorgens and J.H. Knoetze, J. Anal. Appl. Pyrolysis, 96, 24 (2012).

19. M.L. Sekirifa, M. Hadj-Mahammed, S. Pallier, L. Baameur, D. Richard and A.H. Al-Dujaili, J. Anal. Appl. Pyrolysis, 99, 155 (2013).

20. C.J. Duran-Valle, M. Gomez-Corzo, J. Pastor-Villegas and V. GómezSerrano, J. Anal. Appl. Pyrolysis, 73, 59 (2005).

21. J. Guo and A.C. Lua, J. Colloid Interf. Sci., 254, 227 (2002).

22. K. Okada, N. Yamamoto, Y. Kameshima and A. Yasumori, J. Colloid Interf. Sci., 262, 179 (2003).

23. C. Saka, J. Anal. Appl. Pyrolysis, 95, 21 (2012)

24. H. Zhang, Y. Yan and L. Yang, Adsorption, 16, 161 (2010).

25. A. Ahmadpour and D.D. Do, Carbon, 35, 1723 (1997).

26. A. Ahmadpour and D.D. Do, Carbon, 34, 471 (1996).

27. K. Tomkow, T. Siemieniewska, F. Czechowski and A. Jankowska, Fuel, 56, $121(1977)$
28. H. Haykiri-Acma, S. Yaman and S. Kucukbayrak, Energy Convers. Manage., 47, 1004 (2006).

29. V. Fierro, V. Torne-Fernandez and A. Celzard, Stud. Surf. Sci. Catal., 160, 607 (2007).

30. J. Yang, Z. Shen and Z. Hao, Carbon, 42, 1872 (2004).

31. R.S. Al-Juruf, In Proceedings of the 6th Saudi Engineering Conference KFUPM, Dhahran, p. 217 (2002).

32. A. Kumar, L. Wang, Y.A. Dzenis, D.D. Jones and M.A. Hanna, Biomass Bioenergy, 32, 460 (2008).

33. H. Yang, R. Yan, H. Chen, D.H. Lee and C. Zheng, Fuel, 86, 1781 (2007).

34. D.J. Nowakowski, C.R. Woodbridge and J.M. Jones, J. Anal. Appl. Pyrolysis, 83, 197 (2008).

35. D. Kalderis, S. Bethanis, P. Paraskeva and E. Diamadopoulos, Bioresour. Technol., 99, 6809 (2008).

36. A.M. Puziy, O.I. Poddubnaya, A. Martinez-Alonso, F. Suárez-García and J.M.D. Tascón, Carbon, 43, 2857 (2005). 